\title{
AVALIAÇÃO CLÍNICA E DA QUALIDADE DO SONO EM CRIANÇAS COM SÍNDROME DA APNEIA/HIPONÉIA OBSTRUTIVA DO SONO
}

\author{
AUTOR: OLAVO GRANGEIRO DE FRANÇA LINS \\ CO-AUTOR/ORIENTADOR: CLARA MONICA FIGUEREDO DE LIMA
}

\begin{abstract}
Resumo: A Síndrome de Apneia Obstrutiva do Sono (SAOS) é caracterizada por períodos de obstrução total ou parcial das vias aéreas superiores durante o sono e possui etiologia multicausal. A SAOS pode acometer indivíduos de todas as idades, gêneros, etnia e condição social. Na criança, sua prevalência é de $1 \%-3 \%$, sendo considerada uma morbidade relevante para este grupo. As principais manifestações clínicas são roncos, fadiga, irritabilidade e déficit de aprendizado. E possui como fatores de risco: Síndromes, obesidade, malformações anatômicas, hipertrofia amigdaliana, dentre outras. E seu diagnóstico se dá por exame clínico e complementar, sendo que o exame de Polissonografia configura como o padrão ouro. Objetivou-se com este projeto comparar a qualidade do sono de crianças, entre 5-11 anos de idade, asmáticas ou obesas que sejam também portadoras da SAOS. Para isso far-se-á análises comparativas de polissonografias dos grupos em voga, comparando com um grupo controle de crianças com SAOS, de mesma faixa etária, que não possuam doenças crônicas associadas.
\end{abstract}

Palavras-chave: Síndrome da apneia obstrutiva do sono, Otorrinolaringologia. 